\title{
Increased Indoor Exposure to Commonly Used Disinfectants during the COVID-19 Pandemic
}

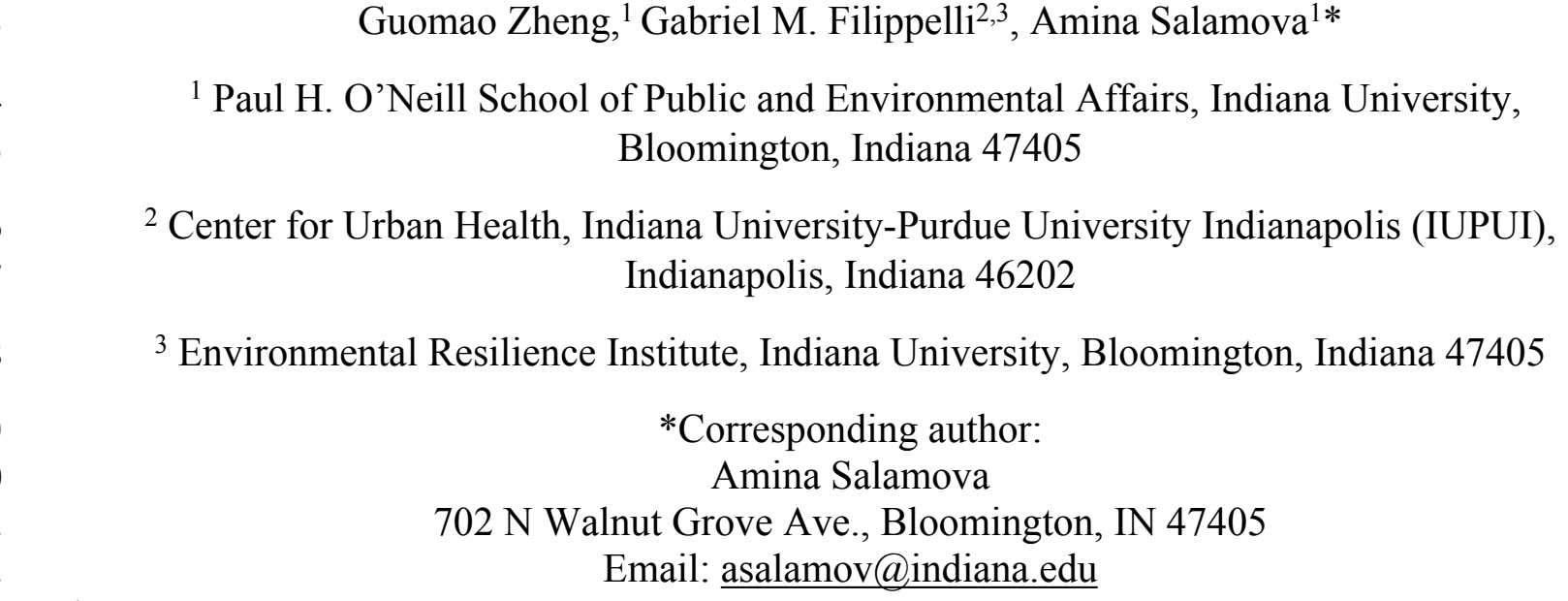

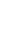

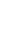

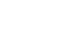

(1)

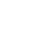

${ }^{1}$ Paul H. O’Neill School of Public and Environmental Affairs, Indiana University,

${ }^{2}$ Center for Urban Health, Indiana University-Purdue University Indianapolis (IUPUI), Indianapolis, Indiana 46202

${ }^{3}$ Environmental Resilience Institute, Indiana University, Bloomington, Indiana 47405

*Corresponding author: Amina Salamova

702 N Walnut Grove Ave., Bloomington, IN 47405

Email: asalamov@indiana.edu

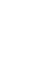

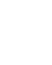

(1)

A

\section{Abstract}

\begin{abstract}
Quaternary ammonium compounds (QACs or "quats") are a class of chemicals used as
\end{abstract} disinfectants in cleaning and other consumer products. While disinfection is recommended for maintaining a safe environment during the COVID-19 pandemic, the increased use of QACs is concerning as exposure to these compounds has been associated with adverse effects on reproductive and respiratory systems. We have determined the occurrence of 19 QACs in residential dust collected before and during the COVID-19 pandemic. QACs were detected in > $90 \%$ of the samples collected during the pandemic at concentrations ranging from $1.95-531 \mu \mathrm{g} / \mathrm{g}$ ( $n=40$, median $58.9 \mu \mathrm{g} / \mathrm{g}$ ). The total QAC concentrations in these samples were significantly higher than in samples collected before the COVID-19 pandemic $(p<0.05 ; n=21$, median 36.3 $\mu \mathrm{g} / \mathrm{g})$. Higher QAC concentrations were found in households that have increased their cleaning routine during the pandemic and in those that generally disinfected more frequently $(p<0.05)$. Disinfecting products commonly used in these homes were analyzed and the QAC profiles in dust and in products were similar, suggesting that these products can be a significant source of QACs.

Our findings indicate that indoor exposure to QACs is widespread and has increased during the pandemic. 


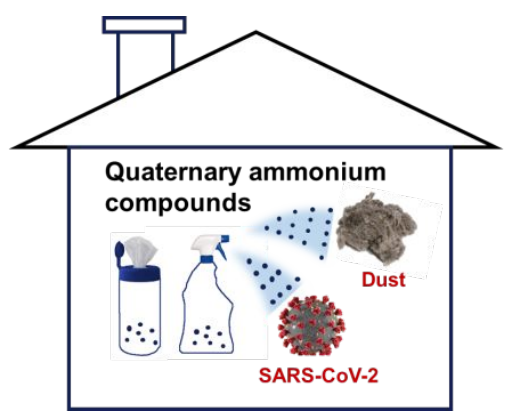

31

32 Increased Indoor Exposure to Commonly Used Disinfectants during the COVID-19

33 Pandemic

34 Guomao Zheng, ${ }^{1}$ Gabriel M. Filippelli²,3, Amina Salamova ${ }^{1 *}$

35

36

*Corresponding author: Amina Salamova

37 Email: asalamov@,indiana.edu

38

39

40

41

42

43

44

45

46

47

48

49

50

51

52 


\section{INTRODUCTION}

The spread of the SARS coronavirus 2 (SARS-CoV-2), which causes the disease COVID-

19, has resulted in a surge in disinfectant use to keep household environments safe..$^{1,2}$ Intensified cleaning protocols during the COVID-19 pandemic specifically call for the increased use of disinfectants in homes and high-risk public spaces, such as schools, health and other care facilities, and food service and work spaces.

Disinfecting products containing quaternary ammonium compounds (QACs), also referred

60 to as "quats", are recommended by the United States Centers for Disease Control and Prevention (CDC) and Environmental Protection Agency (EPA) for disinfecting procedures specifically targeting the SARS-CoV-2. ${ }^{3}$ QACs are the major class of disinfectants and antimicrobials used in cleaning products, biocides, personal care products, and biomedical materials. ${ }^{4,5}$ QACs are salts of quaternary ammonium cations with at least one long hydrophobic hydrocarbon chain substituent and other short-chain substituents, such as methyl or benzyl groups. The three most widely used QAC groups include benzylalkyldimethyl ammonium compounds (BACs, with C6-C18 alkylated chains), dialkyldimethyl ammonium compounds (DDACs, with C8-C18 alkylated chains), and alkyltrimethyl ammonium compounds (ATMACs, with C8-C18 alkylated chains) (Figure S1). Some QACs, including C12-BAC and C14-BAC, are classified by the EPA as high production volume chemicals based on the manufactured or imported amount exceeding 1 million pounds per year. ${ }^{2}$ These compounds are able to disrupt the adipose cell membranes of living organisms and thus the viral envelopes and remove organic material. It is this property in particular that enables QACs to act as disinfectants and antimicrobials. ${ }^{6}$

Exposure to QACs has been associated with several adverse health effects. QACs are recognized as asthmagens, as previous animal and occupational studies have demonstrated that exposure to QACs may lead to a significant increase in asthma triggers and other breathing 
77 problems, such as pulmonary cell damage and inflammation. ${ }^{7,8}$ Skin irritation and decreased

78 fertility were observed in rodents and guinea pigs exposed to some QACs through inhalation and

79 diet. ${ }^{9-13}$ In addition, QACs increase the permeability of outer membranes of living organisms and

80 their long-term use may disrupt the protective lipid membranes of the skin and potentially increase

81 the absorption of toxic substances. ${ }^{14}$ Hence, the increased use of household disinfectants and other

82 cleaning agents containing QACs during the COVID-19 pandemic is of significant concern. ${ }^{2}$

84 Moreover, high levels of QACs have been reported in fruits, food additives, milk, and other dairy

85 products. ${ }^{21-25}$ However, comprehensive studies on their occurrence in the indoor environment are

86 lacking. Household dust has long been recognized as a reservoir and a major human exposure

87 pathway for many environmental contaminants, especially for children. ${ }^{26,27}$ Due to their low

88 volatility, QACs are easily adsorbed to solid airborne particles and dust, where they are unlikely

89 to degrade. This leads to long-term contamination of the indoor environment, which is likely to

90 last long after the pandemic. ${ }^{28}$ Therefore, a better understanding of the increased exposure to QACs

91 during and after the COVID-19 pandemic is essential in order to assess its potential effects on

92 human health.

This is the first study to investigate the occurrence of 19 QACs in residential dust collected

94 before and during the outbreak of COVID-19. In addition, we also measured the levels of QACs

95 in selected disinfecting products commonly used in sampled homes and evaluated the effects of 96 using certain products and disinfection frequency on the levels of QACs in the indoor environment. 
Sample Collection and Analysis. Forty dust samples were collected from residential homes

100

101

102

103

104

105

106

107

108

109

110

112

113

114

115

116

117

118 119 instrumental analysis.

120

121

in Indiana, United States in June 2020 (during the COVID-19 crisis in the United States). In addition, 21 dust samples collected from Indiana homes in 2018-2019 (before the COVID-19 outbreak) were obtained from the archives of the citizen-science program MapMyEnvironment. For both sample groups, dust from vacuum containers and bags (containing dust collected from the entire home) was transferred by the homeowner to resealable bags, delivered or shipped to the laboratory, and stored at room temperature until analysis. Information on the change of disinfecting habits (if disinfecting more frequently since the COVID-19 outbreak), on the disinfection frequency (how many times per month / week), and commonly used cleaning products in sampled homes was also collected at the time of sampling during the pandemic. Cleaning products (sprays and wipes) indicated as frequently used in homes sampled during the pandemic were purchased from local markets for analysis.

All dust samples were sieved using a $500 \mu \mathrm{m}$ mesh size sieve, and approximately $100 \mathrm{mg}$ of dust was transferred to a glass tube, spiked with a surrogate standard $\left(\mathrm{d}_{7}-\mathrm{C} 12-\mathrm{BAC}\right)$, sonicated in $4 \mathrm{~mL}$ of acetonitrile for 1 hour, and centrifuged at $3000 \mathrm{rpm}$ for $5 \mathrm{~min}$. The supernatant was transferred into a clean tube and the residues were re-extracted with $4 \mathrm{~mL}$ of acetonitrile twice. The combined extracts were concentrated to $1 \mathrm{~mL}$ using nitrogen gas and spiked with an internal standard $\left(\mathrm{d}_{7}-\mathrm{C} 14-\mathrm{BAC}\right)$ used for quantification of the target analytes. For the analysis of disinfecting products, $10 \mu \mathrm{L}$ of a product was diluted with $9.99 \mathrm{~mL}$ acetonitrile, and then $1 \mathrm{~mL}$ of the diluted solution was spiked with the internal standard $\left(\mathrm{d}_{7}-\mathrm{C} 14-\mathrm{BAC}\right)$ before the direct

The samples were analyzed using ultra-performance liquid chromatography-triplequadrupole mass spectrometry. The complete analyte list, details of the instrumental analysis, 
122 quality control and assurance measures, and data analysis are provided in the Supporting 123 Information.

\section{RESULTS AND DISCUSSIONS}

Dust Concentrations. Each of the 19 QACs was detected in $>90 \%$ of the samples collected 127 during the COVID-19 pandemic at $\mu \mathrm{g} / \mathrm{g}$ concentration levels (Table 1). The total QAC concentration ( $\sum$ QAC, the sum of 19 QACs) ranged from 1.95 to $531 \mu \mathrm{g} / \mathrm{g}$ (median $58.9 \mu \mathrm{g} / \mathrm{g}$ ).

129 Benzylalkyldimethyl ammonium compounds (BACs) were the major group of QACs found in dust at a median $\sum$ BAC concentration (the sum of 7 BACs) of $27.1 \mu \mathrm{g} / \mathrm{g}$. Dialkyldimethyl ammonium compounds (DDACs) and alkyltrimethyl ammonium compounds (ATMACs) were found at lower concentrations (median $\sum \mathrm{DDAC}$ [the sum of 6 DDACs] $12.3 \mu \mathrm{g} / \mathrm{g}$ and $\sum \mathrm{ATMAC}$ [the sum of 6 ATMACs] $8.78 \mu \mathrm{g} / \mathrm{g})$. BACs, DDACs, and ATMACs accounted for 56,26 , and $18 \%$ of the $\sum$ QAC concentrations, respectively. C12- and C14-BACs were the most abundant QACs, and contributed $29 \%$ and $22 \%$ to the $\sum$ QAC concentrations, respectively. Among the DDACs and ATMACs, C10and C18-DDACs and C16-ATMAC were the most abundant, respectively, and contributed up to $10 \%$ of the $\sum$ QAC concentrations. Overall, these 5 compounds comprised about $80 \%$ of the $\sum$ QAC concentrations. This high proportion is likely related to high production volumes and to the wide application of these individual QACs. ${ }^{15}$ Significant correlations were found among all QAC concentrations (Table S1), suggesting a common source for these compounds.

Similarly, all QACs were detected in $>95 \%$ of the samples collected before the COVID-19

142 outbreak (Table 1), but at significantly lower concentrations than in samples collected during the 143 pandemic (median $36.3 \mu \mathrm{g} / \mathrm{g} ; p<0.05$, Figure 1A). Overall, the dust concentrations of 10 QACs 144 have significantly increased during the pandemic compared to the dust collected pre-pandemic 
145 (Table 1). The median $\Sigma$ QAC concentration in samples collected during the pandemic increased 146 by $62 \%$ when compared to samples collected before the pandemic, with the highest increase of $91 \%$

147 found for BACs. Interestingly, the contributions of BACs, DDACs, and ATMACs to the $\mathrm{QAAC}$ 148 concentrations $(48,30$, and $22 \%$, respectively) in pre-pandemic samples were similar to those

149 found in dust collected during the pandemic, suggesting a similar source of QACs in both sample 150 groups. These results indicate that the levels of QACs in the indoor environment have increased 151 since the outbreak of COVID-19.

When compared with the levels of other environmental contaminants reported in dust from the United States, the median QAC concentration in this study was about 3 times higher than that 154 for organophosphate esters $(16.8 \mu \mathrm{g} / \mathrm{g})^{26}$ and about 1,000 times higher than that for per- and 155 polyfluoroalkyl substances $(84.5 \mathrm{ng} / \mathrm{g}) .{ }^{27} \mathrm{On}$ the other hand, these QAC levels were about 6 times 156 lower than those for phthalates (median $396 \mu \mathrm{g} / \mathrm{g}$ ). ${ }^{29}$ Incidentally, QACs were detected in urban 157 estuarine sediment from New York, United States (median $29 \mu \mathrm{g} / \mathrm{g}$ ) ${ }^{19}$ and in surface sediment from 158 the Great Lakes (2.4 to $4.9 \mu \mathrm{g} / \mathrm{g}$ ), but at lower concentrations than measured here. ${ }^{20}$ These lower 159 environmental levels may be due to the effectiveness of the removal processes at wastewater 160 treatment plants. ${ }^{5}$

Concentrations in Cleaning Products. Table S2 shows the QAC concentrations in 7 cleaning and disinfecting products indicated as commonly used in the homes that were sampled during the

163 pandemic. All three QAC groups were detected in the analyzed products, but at widely varied 164 concentrations. Products 1 and 2 had the highest $\sum$ QAC levels, reaching 16,600 and $1350 \mathrm{mg} / \mathrm{L}$ 165 and accounting for $1.66 \%$ and $0.135 \%$ by weight, respectively (similar to those indicated on the 166 products' labels, $1.2 \%$ and $0.18 \%$ by weight, respectively). These concentrations were $10-1000$ 167 times higher than those in the rest of the products $(2.52-156 \mathrm{mg} / \mathrm{L})$. BACs were the predominant 
168 compounds in Products 1-3, contributing 83, 99, and 98\% to the $\sum$ QAC concentrations (Figure 169 S2). This contribution went down to $0.4-23 \%$ in Products 4-7. It should be noted that Products 1

170 171

172

174

175 176 177 178 179 180 181 182 183 184 185 186 187 188 189 190 and 2 are included in the EPA's $\mathrm{N}$ list of disinfectants effective for the SARS-CoV-2. ${ }^{30}$

The Effect of Disinfecting Practices. Seventy-two percent of participants in this study indicated that they have increased the frequency of disinfecting in their homes since the beginning of the COVID-19 pandemic. Overall, the $\sum$ QAC concentrations in homes with the increased disinfecting frequencies during the COVID-19 crisis (median $65.2 \mu \mathrm{g} / \mathrm{g}$ ) were significantly higher than in homes that did not change their disinfecting routine (median $21.7 \mu \mathrm{g} / \mathrm{g}, p<0.05$ ) (Figure 1B and Table S3), suggesting that the intensified disinfecting practices can significantly increase exposure to QACs in the indoor environment.

The $\sum$ QAC levels in homes that reported cleaning and disinfecting from one to few times a week were significantly higher than in homes that did not do weekly disinfecting or used disinfecting chemicals ( $p<0.05$, Figure $1 \mathrm{C}$ and Table S3). Overall, the homes with higher cleaning frequencies (1-5 times per week) had the $\sum \mathrm{QAC}$ concentration twice as high as homes with less frequent $(<1$ per week or did not use disinfecting products) cleaning (medians $64.6 v s .28 .0 \mu \mathrm{g} / \mathrm{g}$; $p<0.05)$. A linear regression between the average $\sum \mathrm{QAC}$ concentrations of the $10 \mathrm{QACs}$ for which the levels have significantly increased since the COVID-19 outbreak (see Table 1) and the disinfecting frequency in homes was highly significant $\left(\mathrm{r}^{2}=0.9933, p=00034\right.$, Figure S3), further indicating that the disinfecting practices can have a strong effect on the indoor QAC levels.

87 Ninety percent of households reported using a disinfecting product for their cleaning routine, and more than $80 \%$ of these households regularly used Products 1,2 , and 7 . Figure 2 compares the average contributions of BACs, DDAC, and ATMACs in these three products and in dust samples from the homes that regularly used only these three products. These contributions in dust were 
191 similar to those in products $(58,24$, and $18 \%$ vs. 64,14 , and $22 \%$, respectively). The similarity 192 between the profiles in dust and products suggests that disinfecting products frequently used in 193 homes could be a significant source of these compounds.

194 Exposure Assessment. The estimated daily intakes (EDIs) of QACs during the COVID-19 195 pandemic via dust ingestion were calculated for toddlers and adults for the homes with higher 196 disinfecting frequencies (1-5 times per week) and for the homes with less frequent cleaning (less 197 than once a week) (Table 2). The highest $\Sigma$ QAC EDI (615 $\mathrm{ng} / \mathrm{kg}$ bw/day) was found for toddlers 198 in homes with higher disinfecting frequencies and was up to 10 times higher than that estimated 199 for adults. The EDIs for BACs and DDACs were below the tolerable daily intake thresholds for 200 these two compound groups $\left(1 \times 10^{5} \mathrm{ng} / \mathrm{kg}\right.$ bw/day $)$ established by the European Food Safety 201 Authority (EFSA). ${ }^{31}$

Limitations and Implications. This study had several limitations. The sample size was small 203 for both dust and products due to the efforts to finish the study during the time period of the 204 COVID-19 pandemic and the samples were collected from a limited geographic area. Dust was 205 collected by citizen scientists from the vacuum bags and canisters due to the inability to enter the 206 homes during the pandemic and it was not possible to determine which rooms were sampled. The 207 samples collected before the COVID-19 pandemic were collected from different homes than those 208 collected during the pandemic.

Nonetheless, this is the first study to assess human exposure to a wide suite of QACs in the 210 indoor environment. The timing of this study is important considering the increased use of 211 disinfectants due to the current COVID-19 pandemic. Our findings indicate that the indoor 212 exposure to QACs is widespread and significantly higher in households with increased disinfecting 213 frequencies due to the pandemic. The similarity between the profiles of QACs in products and dust 
214 collected from the same households suggests that the disinfecting products are a significant source

215 of these compounds in homes. As the COVID-19 pandemic continues, the use of these compounds

216 is expected to increase worldwide, and more research is needed to confirm our findings in other

217 locations. Furthermore, more intense disinfecting procedures are advised for care facilities, schools,

218 and other high-risk places, many of which serve populations most vulnerable to these exposures.

219 Our findings call for urgent research on risks associated with the increased exposure to these 220 chemicals.

221

222 ACKNOWLEDGMENTS

223 We thank the participating households for donating dust. The MapMyEnvironment program 224 and related sampling effort is partially supported by NSF award ICER-1701132 to Filippelli and 225 the Environmental Resilience Institute, funded by Indiana University's Prepared for 226 Environmental Change Grand Challenge Initiative. Zheng is supported by NIEHS award R01 227 2R01ES019620-06A1. assurance measures; correlations among QAC concentrations in dust; dust QAC concentrations 232 grouped based on the disinfecting frequency; QAC concentrations and patterns in cleaning 233 products; correlation between the disinfecting frequency and QAC dust concentrations. A version 234 of this paper prior to peer review is available on pre-print servers at Indiana University (DOI) ${ }^{32}$ 235 and ChemRxiv (DOI). ${ }^{33}$ 


\section{REFERENCES}

237 (1) U.S. CDC, Cleaning and disinfecting your facility, 2020. Available at: https://www.cdc.gov/coronavirus/2019-ncov/community/disinfecting-building-facility.html (accessed June 7, 2020).

(2) Hora, P. I.; Pati, S. G.; McNamara, P. J.; Arnold, W. A., Increased use of quaternary ammonium compounds during the SARS-CoV-2 pandemic and beyond: Consideration of environmental implications. Environ. Sci. Technol. Lett. 2020.

(3) Bettenhausen, C. A., A chemist's guide to disinfectants, Available at: https://cen.acs.org/safety/consumer-safety/chemists-guidedisinfectants/98/web/2020/05?utm_source=Newsletter\&utm medium=Newsletter\&utm_campai gn=CEN (accessed June 7, 2020). Chemical \& Engineering News 2020.

(4) Makvandi, P.; Jamaledin, R.; Jabbari, M.; Nikfarjam, N.; Borzacchiello, A., Antibacterial quaternary ammonium compounds in dental materials: A systematic review. Dent. Mater. 2018, 34, 851-867.

$250 \quad$ (5) Zhang, C.; Cui, F.; Zeng, G. M.; Jiang, M.; Yang, Z. Z.; Yu, Z. G.; Zhu, M. Y.; Shen, L. Q., Quaternary ammonium compounds (QACs): A review on occurrence, fate and toxicity in the environment. Sci. Total Environ. 2015, 518, 352-362.

(6) Neu, T. R., Significance of bacterial surface-active compounds in interaction of bacteria with interfaces. Microbiol. Rev. 1996, 60, 151-166.

(7) Dumas, O.; Varraso, R.; Boggs, K. M.; Quinot, C.; Zock, J. P.; Henneberger, P. K.; Speizer, F. E.; Le Moual, N.; Camargo, C. A., Jr., Association of occupational exposure to disinfectants with incidence of chronic obstructive pulmonary disease among US female nurses. JAMA network open 2019, 2, 1913563.

259 (8) Swiercz, R.; Hałatek, T.; Wasowicz, W.; Kur, B.; Grzelińska, Z.; Majcherek, W., 260 Pulmonary irritation after inhalation exposure to benzalkonium chloride in rats. Int. J. Occup. Med. Environ. Health 2008, 21, 157-63.

(9) U.S. EPA, Alkyl dimethyl benzyl ammonium chloride (ADBAC) final work plan, 2017. Available at: https://www.regulations.gov/contentStreamer?documentId=EPA-HQ-OPP-20150737-0004\&contentType=pdf. (accessed July 2020).

(10) U.S. EPA, Didecyl dimethyl ammonium chloride (DDAC) final work plan, 2017. Available at: https://www.regulations.gov/contentStreamer?documentId=EPA-HQ-OPP-2015-

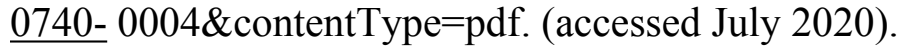

268 (11) Anderson, S. E.; Shane, H.; Long, C.; Lukomska, E.; Meade, B. J.; Marshall, N. B., Evaluation of the irritancy and hypersensitivity potential following topical application of didecyldimethylammonium chloride. J. Immunotoxicol. 2016, 13, 557-566.

(12) Melin, V. E.; Melin, T. E.; Dessify, B. J.; Nguyen, C. T.; Shea, C. S.; Hrubec, T. C., Quaternary ammonium disinfectants cause subfertility in mice by targeting both male and female reproductive processes. Reprod. Toxicol. 2016, 59, 159-166.

281 (15) Mulder, I.; Siemens, J.; Sentek, V.; Amelung, W.; Smalla, K.; Jechalke, S., Quaternary 
ammonium compounds in soil: Implications for antibiotic resistance development. Rev. Environ. Sci. Biotechnol. 2017, 17, 159-185.

(16) Jardak, K.; Drogui, P.; Daghrir, R., Surfactants in aquatic and terrestrial environment: Occurrence, behavior, and treatment processes. Environ. Sci. Pollut. Res. 2016, 23, 3195-3216.

(17) Harrison, K. R.; Kappell, A. D.; McNamara, P. J., Benzalkonium chloride alters phenotypic and genotypic antibiotic resistance profiles in a source water used for drinking water treatment. Environ. Pollut. 2020, 257, 113472.

(18) Li, X.; Doherty, A. C.; Brownawell, B.; Lara-Martin, P. A., Distribution and diagenetic fate of synthetic surfactants and their metabolites in sewage-impacted estuarine sediments. Environ. Pollut. 2018, 242, 209-218.

(19) Li, X.; Brownawell, B. J., Quaternary ammonium compounds in urban estuarine sediment environments - A class of contaminants in need of increased attention? Environ. Sci. Technol. 2010, $44,7561-7568$.

(20) Pati, S. G.; Arnold, W. A., Comprehensive screening of quaternary ammonium surfactants and ionic liquids in wastewater effluents and lake sediments. Environ. Sci. Process Impacts 2020, $22,430-441$.

(21) Xian, Y.; Dong, H.; Wu, Y.; Guo, X.; Hou, X.; Wang, B., QuEChERS-based purification method coupled to ultrahigh performance liquid chromatography-tandem mass spectrometry (UPLC-MS/MS) to determine six quaternary ammonium compounds (QACs) in dairy products. Food Chem. 2016, 212, 96-103.

(22) Yu, L.; Malik, S.; Duncan, T. V.; Jablonski, J. E., High throughput quantification of quaternary ammonium cations in food simulants by flow-injection mass spectrometry. $J . A O A C$ Int. 2018, 101, 1873-1880.

(23) Slimani, K.; Feret, A.; Pirotais, Y.; Maris, P.; Abjean, J. P.; Hurtaud-Pessel, D., Liquid chromatography-tandem mass spectrometry multiresidue method for the analysis of quaternary ammonium compounds in cheese and milk products: Development and validation using the total error approach. J. Chromatogr. A 2017, 1517, 86-96.

(24) BfR opinion No 032/2012, 2012. Health assessment of benzalkonium chloride residues in food.

(25) BfR opinion No 027/2012, 2012. Health assessment of didecyldimethylammonium chloride (DDAC) residues in food.

(26) Vykoukalová, M.; Venier, M.; Vojta, Š.; Melymuk, L.; Bečanová, J.; Romanak, K.; Prokeš, R.; Okeme, J. O.; Saini, A.; Diamond, M. L.; Klánová, J., Organophosphate esters flame retardants in the indoor environment. Environ. Int. 2017, 106, 97-104.

(27) Karásková, P.; Venier, M.; Melymuk, L.; Bečanová, J.; Vojta, Š.; Prokeš, R.; Diamond, M. L.; Klánová, J., Perfluorinated alkyl substances (PFASs) in household dust in Central Europe and North America. Environ. Int. 2016, 94, 315-324.

(28) LeBouf, R. F.; Virji, M. A.; Ranpara, A.; Stefaniak, A. B., Air and surface sampling method for assessing exposures to quaternary ammonium compounds using liquid chromatography tandem mass spectrometry. Ann. Work Expo. Health 2017, 61, 724-736.

(29) Guo, Y.; Kannan, K., Comparative assessment of human exposure to phthalate esters from house dust in China and the United States. Environ. Sci. Technol. 2011, 45, 3788-3794.

(30) U.S. EPA, List N: Disinfectants for use against SARS-CoV-2 (COVID-19), 2020. Available at: https://www.epa.gov/pesticide-registration/list-n-disinfectants-use-against-sars-cov2-covid-19 (accessed June 20, 2020).

(31) European Food Safety Authority, Reasoned opinion on the dietary risk assessment for 
328 proposed temporary maximum residue levels (MRLs) of didecyldimethylammonium chloride 329 (DDAC) and benzalkonium chloride (BAC). EFSA Journal 2014, 12, 3675.

330 (32) Zheng, G. M.; Filippelli, G.; Salamova, A., Indoor exposure to commonly used 331 disinfectants during the COVID-19 pandemic. Available at: 332 https://scholarworks.iupui.edu/handle/1805/23522. Preprint, Indiana University 2020.

333 (33) Zheng, G. M.; Filippelli, G.; Salamova, A., Indoor exposure to commonly used 334 disinfectants during the COVID-19 pandemic. Available at: 335 https://doi.org/10.26434/chemrxiv.12567746.v1. Preprint, ChemRxiv 2020. 
Table 1. Detection frequencies (DF, \%), minimum (min), maximum (max), and median concentrations ( $\mu \mathrm{g} / \mathrm{g})$ of QACs in residential dust collected before $(n=21)$ and during $(n=40)$ the COVID-19 pandemic, contribution (contr, \%) of each QAC to the $\Sigma$ QAC concentrations, and percent change in concentrations measured in these two sample groups (based on median concentrations). MDL: method detection limit. The asterisks represent the statistical difference at $p<0.05$ based on a Mann-Whitney test.

\begin{tabular}{|c|c|c|c|c|c|c|c|c|c|c|c|}
\hline \multirow[b]{2}{*}{ QACs } & \multicolumn{5}{|c|}{ Before the COVID-19 } & \multicolumn{5}{|c|}{ During the COVID-19 } & \multirow{2}{*}{ Change, $\%$} \\
\hline & DF & Min & Max & Median & Contr & DF & Min & Max & Median & Contr & \\
\hline \multicolumn{12}{|l|}{$\underline{B A C S}$} \\
\hline C6-BAC & 95 & $<\mathrm{MDL}$ & 0.015 & 0.00171 & 0.01 & 98 & $<\mathrm{MDL}$ & 0.084 & 0.004 & 0.01 & $134 *$ \\
\hline C8-BAC & 100 & 0.0022 & 12.2 & 0.0496 & 0.2 & 100 & 0.0022 & 7.58 & 0.058 & 0.1 & 17 \\
\hline C10-BAC & 100 & 0.0040 & 0.329 & 0.0213 & 0.1 & 100 & 0.0005 & 0.787 & 0.054 & 0.1 & $154^{*}$ \\
\hline C12-BAC & 100 & 1.40 & 32.5 & 5.89 & 25 & 100 & 0.244 & 181 & 12.6 & 29 & $114^{*}$ \\
\hline C14-BAC & 100 & 0.863 & 30.9 & 3.88 & 16 & 100 & 0.760 & 154 & 9.55 & 22 & $146^{*}$ \\
\hline C16-BAC & 100 & 0.181 & 9.73 & 1.03 & 4.3 & 100 & 0.203 & 75.6 & 3.17 & 7.2 & $208 *$ \\
\hline C18-BAC & 100 & 0.0393 & 6.07 & 0.431 & 1.8 & 100 & 0.061 & 34.8 & 1.16 & 2.6 & $169 *$ \\
\hline$\sum \mathbf{B A C}$ & 100 & 3.19 & 74.2 & 14.2 & 48 & 100 & 1.66 & 421 & 27.1 & 56 & $91 *$ \\
\hline \multicolumn{12}{|l|}{$\underline{D D A C s}$} \\
\hline C8-DDAC & 100 & 0.056 & 7.33 & 1.10 & 4.6 & 100 & 0.0148 & 20.2 & 1.63 & 3.7 & 48 \\
\hline C10-DDAC & 100 & 1.09 & 24.1 & 5.53 & 23 & 100 & 0.0219 & 32.8 & 4.30 & 10 & -22 \\
\hline C12-DDAC & 95 & $<\mathrm{MDL}$ & 0.139 & 0.0495 & 0.2 & 98 & $<\mathrm{MDL}$ & 2.91 & 0.047 & 0.1 & -5 \\
\hline C14-DDAC & 95 & $<\mathrm{MDL}$ & 0.050 & 0.0147 & 0.1 & 100 & 0.0002 & 0.462 & 0.016 & 0.04 & 9 \\
\hline C16-DDAC & 100 & 0.0355 & 4.67 & 0.231 & 1.0 & 100 & 0.0031 & 4.24 & 0.374 & 0.9 & 62 \\
\hline C18-DDAC & 100 & 0.0809 & 22.1 & 1.71 & 7.0 & 100 & 0.0192 & 33.1 & 3.47 & 7.9 & $103 *$ \\
\hline$\sum$ DDAC & 100 & 1.35 & 41.4 & 8.87 & 30 & 100 & 0.0595 & 68.9 & 12.3 & 26 & 39 \\
\hline \multicolumn{12}{|l|}{$\underline{A T M A C s}$} \\
\hline C8-ATMAC & 100 & 0.0007 & 0.253 & 0.0223 & 0.1 & 95 & $<\mathrm{MDL}$ & 0.507 & 0.057 & 0.1 & $156^{*}$ \\
\hline C10-ATMAC & 100 & 0.0146 & 2.41 & 0.196 & 0.8 & 93 & $<\mathrm{MDL}$ & 6.76 & 0.266 & 0.6 & 36 \\
\hline C12-ATMAC & 100 & 0.0166 & 22.5 & 0.758 & 3.2 & 100 & 0.0281 & 13.1 & 1.25 & 2.9 & 65 \\
\hline C14-ATMAC & 95 & $<\mathrm{MDL}$ & 4.05 & 0.131 & 0.5 & 100 & 0.0034 & 2.51 & 0.275 & 0.6 & $110^{*}$ \\
\hline C16-ATMAC & 100 & 0.246 & 14.0 & 2.20 & 9.3 & 100 & 0.0116 & 61.3 & 4.59 & 10 & $109 *$ \\
\hline C18-ATMAC & 100 & 0.030 & 6.32 & 0.546 & 2.3 & 100 & 0.0096 & 9.80 & 0.841 & 1.9 & 54 \\
\hline$\sum$ АTМАC & 100 & 0.698 & 26.1 & 6.36 & 22 & 100 & 0.235 & 66.5 & 8.78 & 18 & 38 \\
\hline$\sum \mathbf{Q A C}$ & 100 & 6.55 & 127 & 36.3 & 100 & 100 & 1.95 & 531 & 58.9 & 100 & $62 *$ \\
\hline
\end{tabular}


342 Table 2. Estimated daily intakes (EDIs; $\mathrm{ng} / \mathrm{kg}$ body weight [bw]/day) of each QAC group via dust 343 ingestion for toddlers and adults in homes with more frequent (1-5 times per week) and less 344 frequent (less than once a week or do not use disinfecting chemicals) disinfecting during the 345 COVID-19 pandemic.

\begin{tabular}{ccccc}
\hline & \multicolumn{2}{c}{ More disinfecting } & \multicolumn{2}{c}{ Less disinfecting } \\
\hline & Toddlers & Adults & Toddlers & Adults \\
SBAC & 423 & 36.3 & 94.9 & 8.13 \\
IDDAC & 106 & 9.07 & 64.8 & 5.55 \\
IATMAC & 86.7 & 7.43 & 46.2 & 3.96 \\
EQAC & 615 & 52.7 & 206 & 17.6 \\
\hline
\end{tabular}




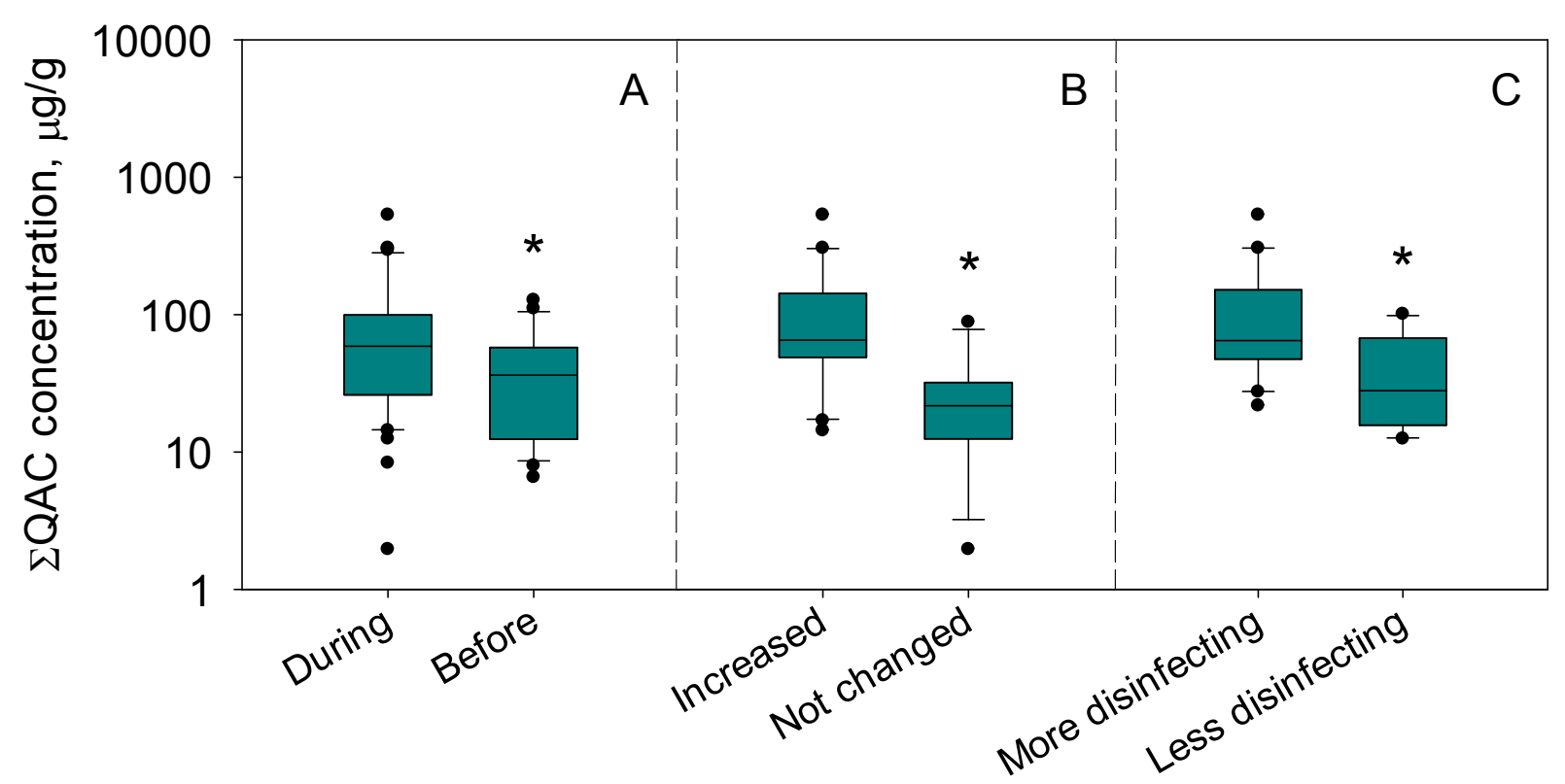

Figure 1. The $\sum \mathrm{QAC}$ concentrations $(\mu \mathrm{g} / \mathrm{g})$ in dust collected from homes: A) during $(n=40)$ and before $(n=21)$ the COVID-19 pandemic; B) with increased $(n=29)$ and not changed $(n=11)$ disinfecting frequency during the COVID-19 pandemic; and C) more frequent (1-5 times per week; $n=27$ ) and less frequent (less than once a week or do not use disinfecting chemicals; $n=13$; three outliers were omitted) disinfecting. Concentrations are shown as boxplots, representing the $25^{\text {th }}$ and $75^{\text {th }}$ percentiles; black lines represent the median; and the whiskers represent the $10^{\text {th }}$ and $90^{\text {th }}$ percentiles. The asterisks represent the statistical difference at $p<0.05$ based on a Mann-Whitney test. 


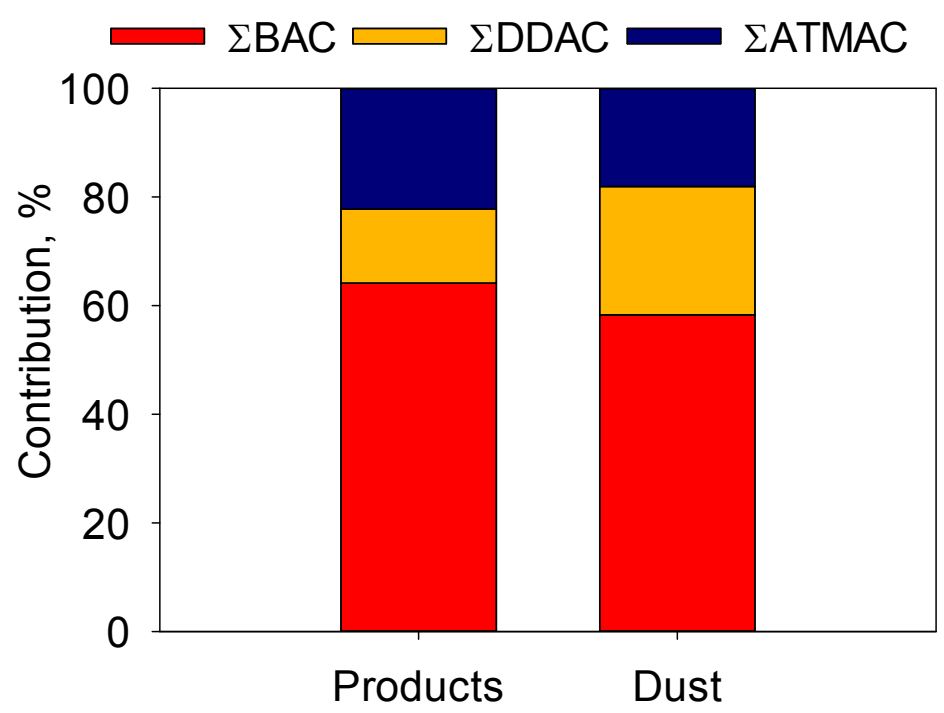

Figure 2. Comparison of the average contributions (\%) of the three QAC groups to the $\sum$ QAC concentrations in house dust and in the only three disinfecting products (Products 1, 2, and 7) used in more than $80 \%$ of the homes. 